\title{
Dynamic Rock-Breaking Process of TBM Disc Cutters and Response Mechanism of Rock Mass Based on Discrete Element
}

\author{
Qinglong Zhang $\mathbb{D}^{1},{ }^{1}$ Yanwen Zhu, ${ }^{1}$ Canxun Du, ${ }^{2}$ Sanlin Du, ${ }^{2}$ Kun Shao, ${ }^{2}$ and Zhihao Jin ${ }^{1}$ \\ ${ }^{1}$ Department of Civil Engineering, School of Civil and Resource Engineering, University of Science and Technology Beijing, \\ Beijing 100083, China \\ ${ }^{2}$ Huaneng Tibet Hydropower Safety Engineering Technology Research Center, Tibet, China \\ Correspondence should be addressed to Qinglong Zhang; qlzhang@ustb.edu.cn
}

Received 9 December 2021; Accepted 27 December 2021; Published 11 January 2022

Academic Editor: Mingfeng Lei

Copyright (c) 2022 Qinglong Zhang et al. This is an open access article distributed under the Creative Commons Attribution License, which permits unrestricted use, distribution, and reproduction in any medium, provided the original work is properly cited.

\begin{abstract}
Rock-breaking efficiency of full-face rock tunnel boring machine (TBM) is closely related to the performance of the disc cutter and the characteristics of the rock mass. In the point of view of mesomechanics, the particle flow code (PFC) is used to establish a numerical model of the rock mass and the disc cutter, and the process of TBM disc cutter intrusion into the rock mass is analyzed. The dynamic response mechanism and crack evolution process of the rock mass under the action of the disc cutter are studied on the basis of micromechanics, and the relationship between the rock mass crack, penetration, and cutting force during the intrusion of the disc cutter is revealed. The sensitivity analysis is carried out on the confining pressure conditions and the influence parameters of the disc cutter spacing. The results show that the rock breaking by disc cutter undergoes the transformation characteristics of compaction, shearing, and tension failure modes, and the failure process of the rock mass is the joint action of tension and shear. In the whole process of rock breaking, the disc cutter has the phenomenon of repeated loading-unloading alternation and leaping rock breaking; after the penetration of the disc cutter reached $9.0 \mathrm{~mm}$, penetration creaks begin to appear on the surface of the rock mass; the penetration was obviously reduced with the increase of confining pressure, and it is mainly the penetration cracks on the surface; after the disc cutter spacing reaches $100.0 \mathrm{~mm}$, there is no penetration crack between the two disc cutters. The research conclusion can provide a reference for the disc cutter optimization design.
\end{abstract}

\section{Introduction}

Full-face rock tunnel boring machine (TBM) has been widely used in mining engineering, water conservancy and hydropower tunnels, highway tunnels, and other projects. The disc cutter, at the foremost end of TBM, is an important part of TBM, which determines whether it can effectively break rock and directly generate load on the surrounding rock to cause dynamic damage to the rock mass. In order to better achieve the destructive effect, the generation, propagation, failure mechanism, and mode transformation of rock cracks have become a hot topic that many scholars pay attention to, and it is of great significance to how to optimize the design of the disc cutter for efficient rock breaking [1-5].
In terms of the interaction between the disc cutter and the surrounding rock, around the rock-breaking mechanism of the TBM disc cutter, the predecessors have carried out relevant research works from the perspectives of theoretical analysis, indoor linear cutting machine test, and numerical simulation [6-17]. However, due to the hypothetical limitations of theoretical analysis, the high cost of laboratory tests, and the difficulty in dynamically observing crack propagation changes, it is difficult to effectively analyze the rock-breaking mechanism and interaction process of the disc cutter. Numerical software has been gradually applied to scientific research due to its low computational cost, easy real-time observation of the state, and multifactor simulation experiments $[18,19]$. Some scholars have achieved some research results by using the discrete medium mechanics method 
[20-26]. Oñate and Rojek [27] analyzed the dynamic behavior of cutting geological rocks by the discrete element method. Kou et al. $[28,29]$ made a comprehensive study on the rock failure mode, the chip formation process, and the relationship between cutting force and displacement. Gong et al. [30] studied the rock fragmentation mode under the action of the disc cutter through the disc cutter intrusion discrete element model. Kong et al. [31] operated the particle flow code (PFC) to establish a rock-cutting model and then analyzed the effects of different joint orientations. Moon and Oh [32] simulated the crack formation process induced by multi-indenters to study the optimum cutting conditions by PFC-2D. Choi and Lee [33] employed PFC to simulate three-dimensional dynamic fracturing failure of rock.

In terms of failure mechanism, many researchers have put forward different explanations, mainly including three theories of shear mechanism, tension mechanism, and comprehensive action mechanism. Some scholars believe that it is a composite process of shear failures and tensile failures. In 1966, Maurer [34], Cheatham and Gnirk [35], and Gnirk [36] revealed that there are both shear failure and tensile failure when the disc cutter acts on rocks. In 1975, Lawn and Wilshaw [37] believed that the brittle materials formed a block due to cracks caused by stretching under the action of the indenter. Cook et al. [38] simulated the rock intrusion process of the circular flat heads through a twodimensional symmetric linear elastic finite element model.

In terms of rock-breaking simulation with TBM disc cutter, the particle discrete element method focuses on the analysis of the damage and fracture mechanism of materials from the perspectives of the mesoscale mechanism, which can realize the numerical experiment and analysis of the mesobrittle fracture mechanism and progressive failure process of rock materials [39]. In the rock-breaking simulation of the disc cutter, the accurate simulation of the crack generation and propagation process is particularly important for revealing the rock-breaking mechanism. The existing simulation studies mostly use the development of the plastic zone instead of the rock crack range [7, 40-44], which cannot truly reflect the generation and propagation of radial and longitudinal cracks and the separation process between rock slices after the disc cutter is pressed into the rock. In this paper, the particle flow code (PFC) [45], which can better simulate the crack propagation of rock (body), is adopted. Based on the study and analysis of the rock-breaking mechanism of the TBM disc cutter, the dynamic response mechanism of rock mass under the action of the TBM disc cutter is studied by the particle discrete element method from the mesopoint of view. And the influence of the confining pressure conditions and the disc cutter spacing on the rock crack properties, quantity, disc cutter reaction force, rock-breaking effect, etc., are further simulated and analyzed. The research results can provide a reference for TBM type selection and disc cutter design.

\section{Rock Parameter Calibration}

As a numerical simulation method based on discontinuous medium theory and mesomechanics, the particle discrete element method can simulate the failure mechanism of rock materials from the perspective of mesomechanics and simultaneously reflect the micro-mesostructure characteristics and macromechanical behavior of materials. The simulation of the physical prototype by the particle flow method is mainly completed by defining the mesoparameters and macroboundary conditions of particle bonding. However, its mesoparameters generally cannot be directly and simply connected with the macroscopic physical and mechanical parameters of the rock. The macroparameters are affected by multiple mesoparameters. Currently, it is impossible to deduce the accurate quantitative relationship between macroparameters and mesoparameters from a theoretical perspective. Meanwhile, it is difficult to directly measure mesoparameters through laboratory or onsite tests. Therefore, it is necessary to calibrate the mesoparameters. Generally, uniaxial compression and Brazilian splitting tests can be used to determine the macroscopic parameters that characterize rock mechanical behavior, mainly including uniaxial compressive strength $f_{c}$, tensile strength $t_{c}$, elastic modulus $E$, and Poisson's ratio $v$.

It is calibrated using the results of uniaxial compression and the Brazilian splitting test of marble (diameter $\times$ height: $50 \mathrm{~mm} \times 100 \mathrm{~mm}$ and $50 \mathrm{~mm} \times 25 \mathrm{~mm}$, respectively). The macrophysical and mechanical parameters of the marble in the laboratory test are shown in Table 1, and the mesomechanical parameters of the calibrated particle flow model are shown in Table 2. The maximum and minimum particle radius ratio $\left(R_{\max } / R_{\min }\right)$ is 2.0 , and the minimum particle radius is $1.2 \mathrm{~mm}$. Figure 1 shows the stress-strain curve and the failure of the rock sample in the uniaxial compression and Brazilian splitting tests under corresponding mesoparameters. It can be seen from the figure that the rock sample in the uniaxial compression numerical test has a conical splitting failure, while the rock sample in the Brazilian splitting numerical test has a central crack penetration failure. The stress-strain curve, failure shape, and peak strength are all consistent with the laboratory test results. The calibrated parameters can be used to analyze the rockbreaking mechanism of the disc cutter.

\section{Simulation of Rock Fragmentation by TBM Disc Cutters}

3.1. Results and Analysis. In the process of rock breaking, the disc cutter ring contacts the rock, and the rock is penetrated by the pressure of the cutter head, and cracks are generated to achieve the purpose of rock breaking. The commonly used 17 -inch disc cutter is adopted, the wall combination is used to simulate the disc cutter ring, and the model is $200.0 \mathrm{~mm}$ wide and $100.0 \mathrm{~mm}$ high. Through the servo mechanism of the upper and lower walls, preloading consolidation is performed to simulate the natural formation process of the rock mass. The left, right, and bottom walls of the sample are all rigidly constrained to limit the displacement of the rock mass. After stabilization, the top rigid wall is deleted and the stress is released, which is consistent with the on-site TBM tunneling conditions [46]. The intrusion speed of the disc cutter is set to $0.5 \mathrm{~mm} / \mathrm{s}$ and the final penetration to $15.0 \mathrm{~mm}$, the macro- and microinformation of the rock 
TABLE 1: Macroscopic physical and mechanical parameters of rock materials.

\begin{tabular}{lcccc}
\hline Density $\rho\left(\mathrm{kg} / \mathrm{m}^{3}\right)$ & Elastic modulus $E(\mathrm{GPa})$ & Uniaxial tensile strength $f_{c}(\mathrm{MPa})$ & Tensile strength $t_{c}(\mathrm{MPa})$ & Poisson's ratio $v$ \\
\hline 2420.0 & 24.0 & 93.5 & 10.9 & 0.24 \\
\hline
\end{tabular}

TABLE 2: Mesomechanical parameters of the particle flow model. Density $\rho\left(\mathrm{kg} / \mathrm{m}^{3}\right)$ Normal stiffness (GPa) Tangential stiffness (GPa) Normal strength (MPa) Tangential strength (MPa) Frictional

\begin{tabular}{llllll}
\hline 2420.0 & 18.0 & 18.0 & 55.0 & 35.0 & 0.5
\end{tabular}

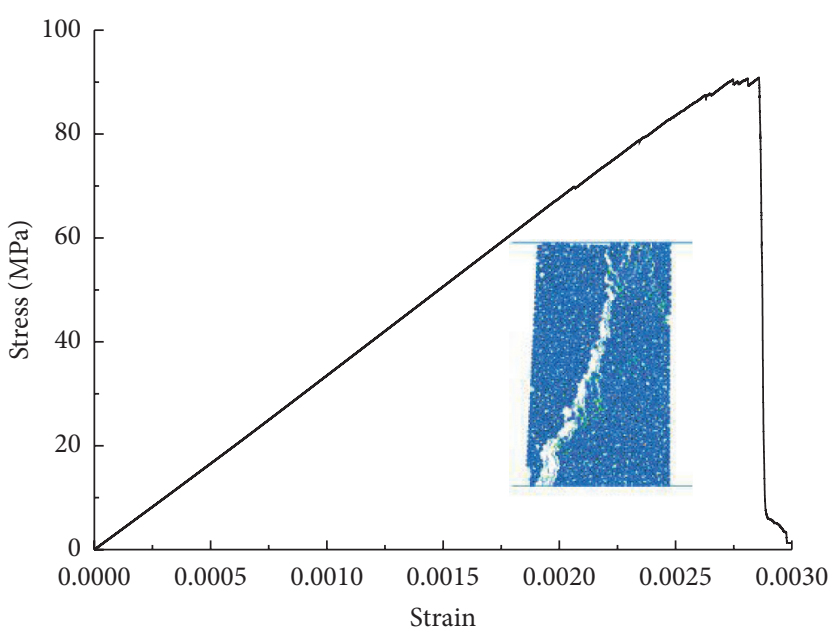

(a)

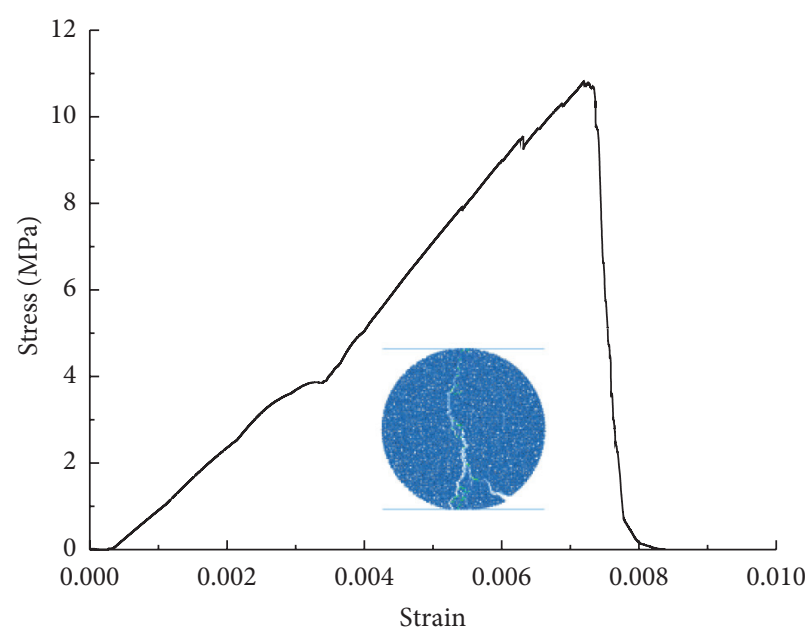

(b)

FIGURE 1: Calibration of mesoparameters of the particle flow model: (a) uniaxial compression compressive strength calibration; (b) Brazilian splitting tensile strength calibration.

sample are recorded during the entire intrusion process. Figure 2 shows the generation and expansion process of cracks and rock failure under the action of thrust at different penetration depths.

It can be seen from the figure that when the disc cutter penetrates $1.0 \mathrm{~mm}$, microcracks are generated under the disc cutter. When the disc cutter penetrates $3.0 \mathrm{~mm}$, the compressive stress is concentrated due to the obvious extrusion effect of the disc cutter on the rock mass, and the microcracks under the disc cutter begin to form penetrating diameter and lateral cracks. When penetrating $6.0 \mathrm{~mm}$, the rock mass is continuously squeezed and fractured, and long cracks begin to form. This kind of fracture cannot reach the peeling off of the rock, but it is an inevitable process for the disc cutter to press into the rock. At $9.0 \mathrm{~mm}$, a semicircular plastic failure zone is formed around the disc cutter, and a part of the lateral cracks gradually expands, and microcracks are formed on the surface of the rock without the action of the disc cutter, which intersects with the rock surface to form a through crack. At $12.0 \mathrm{~mm}$, the large intact rock fragments on both sides of the disc cutter separated from the rock mass and began to fall off. With the increase of penetration, the increasing trend of failure area slows down to $15.0 \mathrm{~mm}$, but the radial and lateral cracks still expand to a certain extent. In summary, after the penetration is $12.0 \mathrm{~mm}$, the crack propagation effect is not obvious by increasing the penetration.
The change of vertical force of the disc cutter during penetration is shown in Figure 3. At the initial stage of penetration, the vertical force of the disc cutter increases nearly linearly with the increase of penetration. When the penetration reaches $1.0 \mathrm{~mm}$, the vertical force drops abruptly, and the disc cutter begins to unload. However, the vertical force fluctuating up and down during the entire penetration indicates that the disc cutter has the alternating state of loading and unloading repeatedly, and the rockbreaking phenomenon of leaping forward is shown in the actual process. The main reason is that extrusion and collapse occur under the action of vertical force, and the resistance suddenly decreases. When the disc cutter continues to penetrate, the rock particles continue to peel off at the front end of the blade, and a small volume of rock debris falls out, resulting in a small range of fluctuation of vertical cutting force. In the vertical force curve, the rising stage of the curve indicates that the disc cutter penetrates the rock mass, and the disc cutter force continues to rise with the increase of penetration depth. In the meanwhile, the rock sample gradually forms broken zones, microcracks, and macrocracks and tends to penetrate. When the macrocracks penetrate to form the rock fragments and separate them from the rock mass, it causes the "void" phenomenon of the cutter, the disc cutter force dropped sharply, and a "leap forward" fracture of the rock occurs. After continuous small- 


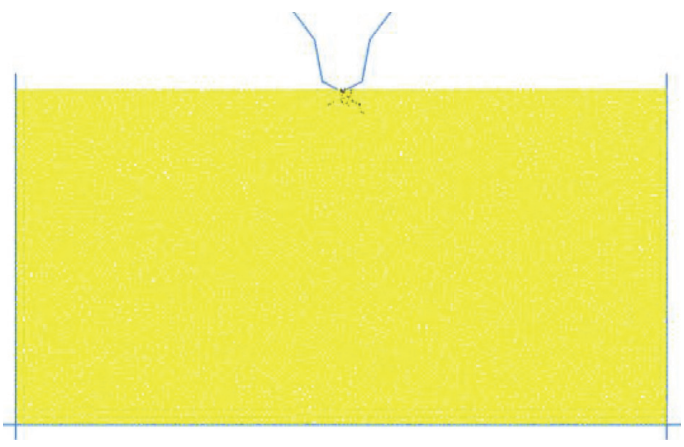

(a)

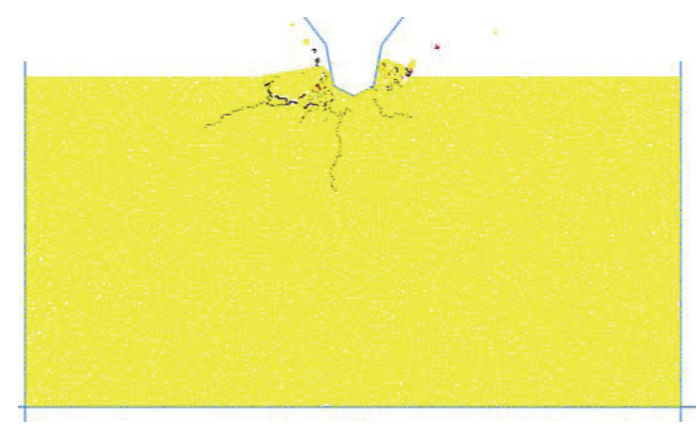

(c)

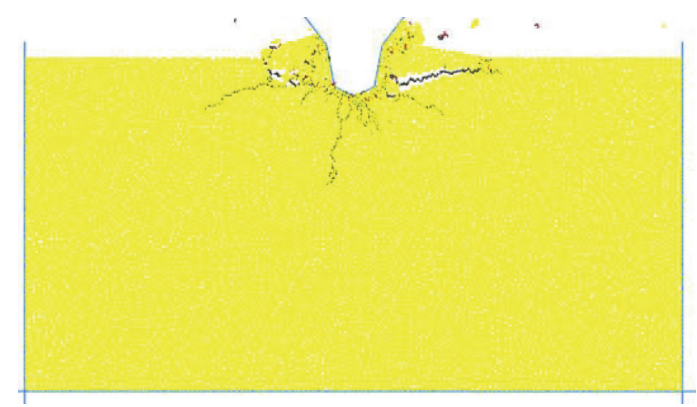

(e)

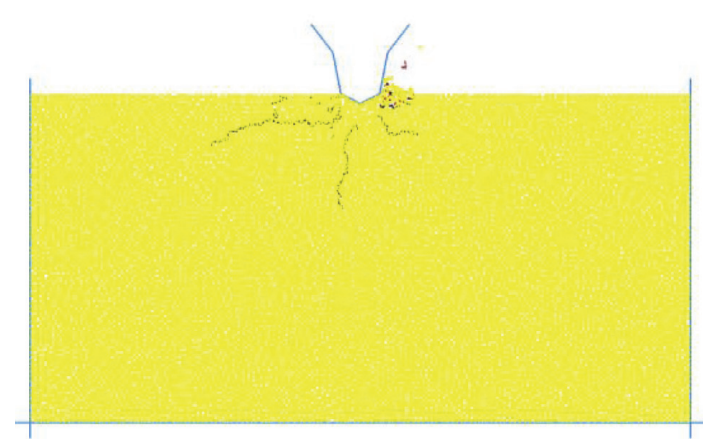

(b)

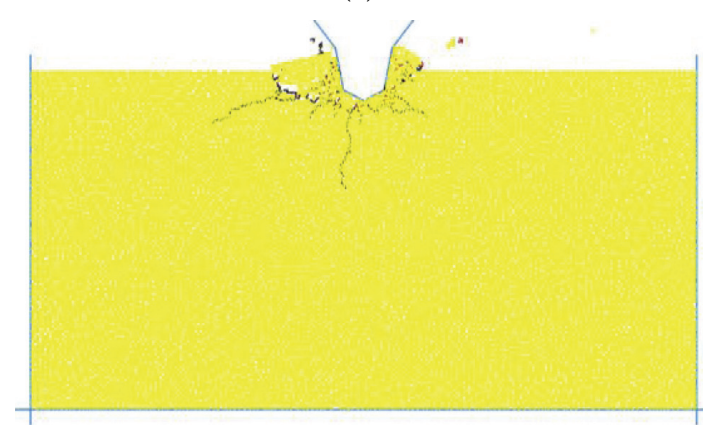

(d)

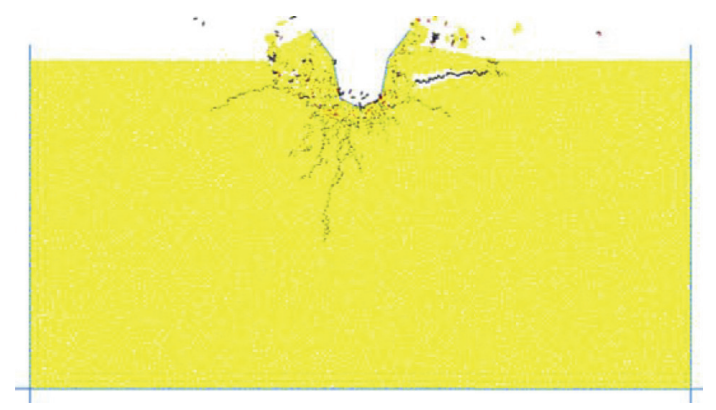

(f)

FIGURE 2: Failure characteristics of rock mass during rock breaking by disc cutter. (a) Intrusion $1.0 \mathrm{~mm}$. (b) Intrusion $3.0 \mathrm{~mm}$. (c) Intrusion $6.0 \mathrm{~mm}$. (d) Intrusion $9.0 \mathrm{~mm}$. (e) Intrusion $12.0 \mathrm{~mm}$. (f) Intrusion $15.0 \mathrm{~mm}$.

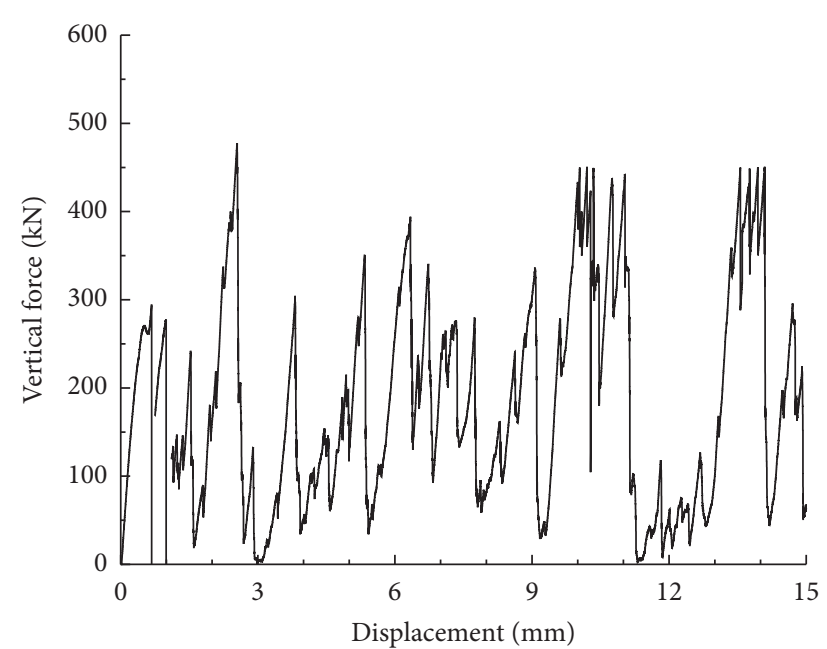

FIGURE 3: Vertical force in the rock-breaking process of disc cutter. 
volume disintegration, the contact area between the disc cutter and the rock gradually increases, until the full-width contact is reached, and another large collapse occurs. Therefore, the process of the disc cutter intruding into the rock is a continuous cycle composed of several small collapses and one large collapse, which leads to the leap forward crushing of the rock under the action of the disc cutter.

3.2. Discussion on Mesomechanism of Rock Breaking by Disc Cutter. Compared with other numerical methods, PFC has unique advantages in the analysis of mesocharacteristics. It can monitor the mesoforce field and the development and evolution process of microcracks in the process of rock deformation and failure in real time and can reveal the mesomechanism of rock breaking by the disc-shaped disc cutter.

The change of the number of microcracks during the intrusion of the disc cutter is shown in Figure 4. During the initial penetration, the main result of the compression under the disc cutter is the formation of a dense core. Meanwhile, the number of cracks is small. With the increase of the penetration load, microcracks increase sharply. In a certain period, the cracks increase by leaps, and the phenomenon of leaping growth becomes more obvious in the later period of penetration, indicating that the cracks expand rapidly to form a large number of broken rock blocks in the process of rock fracture. Both tensile and shear cracks appear in the rock-breaking process of the disc cutter, indicating that this process is a joint failure mode of tension and shear. The number of shear cracks is always greater than that of tensile cracks, and the final number of shear microcracks is nearly 5 times that of tensile microcracks. The whole rock-breaking process is dominated by shear microcracks.

Figure 5 shows the distribution characteristics of tensile and shear cracks in the process of rock mass rupture. Red represents tensile cracks, and black represents shear cracks. Tensile and shear cracks appear simultaneously in the failure area under the edge of the disc cutter, with more shear cracks and fewer tensile cracks. Under continuous loading, the cracks gradually extend downwards, and then, the tensile cracks and shear cracks under the disc cutter increase rapidly, forming a concentrated failure powder core area. The cracks far away from the disc cutter are mostly shear cracks, which are similar to uniaxial compression, indicating that the shear action in the rock-breaking process dominates the propagation and development of the cracks and ultimately leads to the deep failure of the rock mass and the generation of large rock slag. The rock breaking by the disc cutter undergoes the transformation characteristics of compaction, shear, and tension failure modes.

\section{Sensitivity Analysis of Influencing Parameters}

4.1. Different Confining Pressures. Confining pressure conditions affect the generation and propagation of cracks, lead to different fracture modes, and then macroscopically affect the rock-breaking effect of the disc cutter. To explore the rock-breaking mechanism and its influence on the rock-

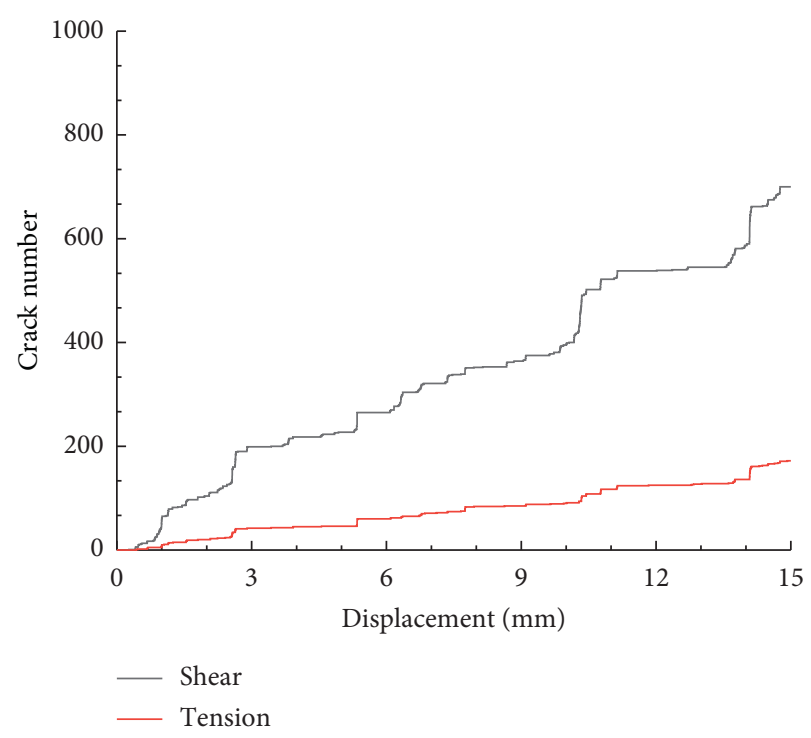

Figure 4: Number of cracks in the rock-breaking process of the disc cutter.

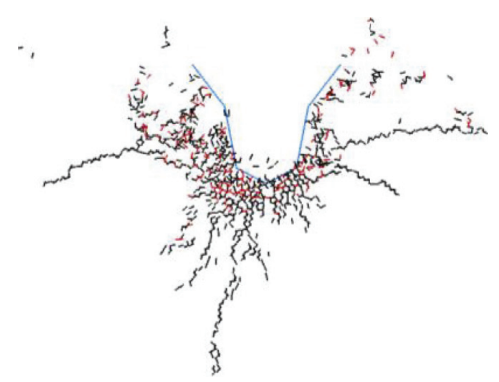

FIGURE 5: Failure characteristics of rock mass in the process of rock breaking by disc cutter.

breaking effect under different burial depths, the particle flow simulation of single disc cutter intrusion into fractured rock mass under different confining pressures was carried out. The confining pressure is set to $0.0,10.0,20.0,30.0$, and $40.0 \mathrm{MPa}$, respectively.

As shown in Figure 6, when the confining pressure is low, the longitudinal cracks develop obviously and develop deep into the rock mass, the damage depth of the rock mass is relatively large, and the development of transverse cracks is not obvious, mainly manifested in the fracture of the rock mass around the cutterhead. With the increase of the confining pressure, the longitudinal crack propagation is restrained, mainly to the transverse crack, the damage depth of the rock mass is small, and the transverse crack propagates obviously and gradually penetrates to form a large block falling off. Although high confining pressure is not conducive to the development of longitudinal cracks, it is more favorable to the development of lateral cracks. The cracks gradually extend to the free surface of the rock mass and are easy to intersect with the cracks generated by the adjacent disc cutters to generate exfoliated rock fragments. However, the radial crack expansion depth is small, and the overall rock-breaking effect is not ideal. 


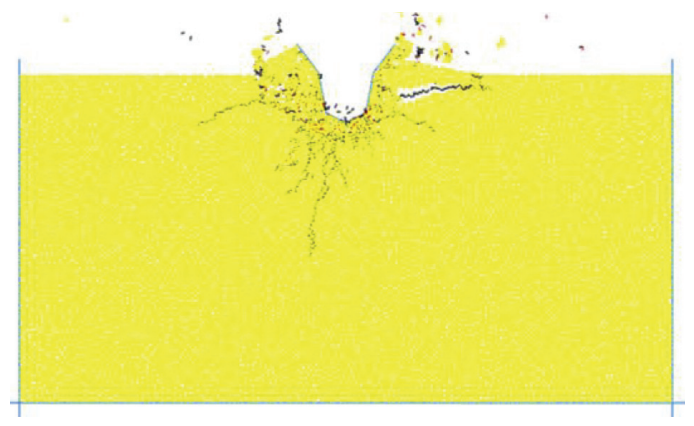

(a)

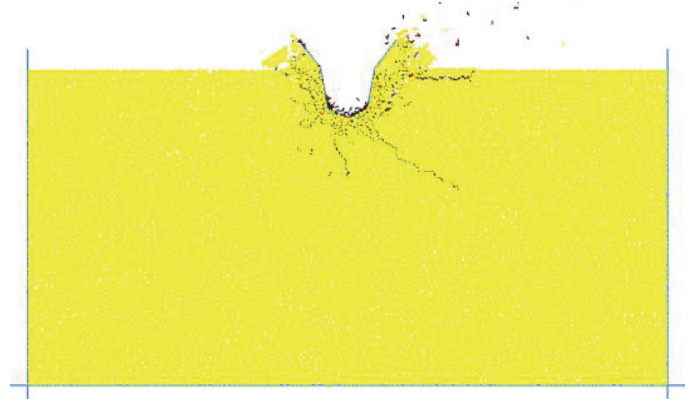

(c)

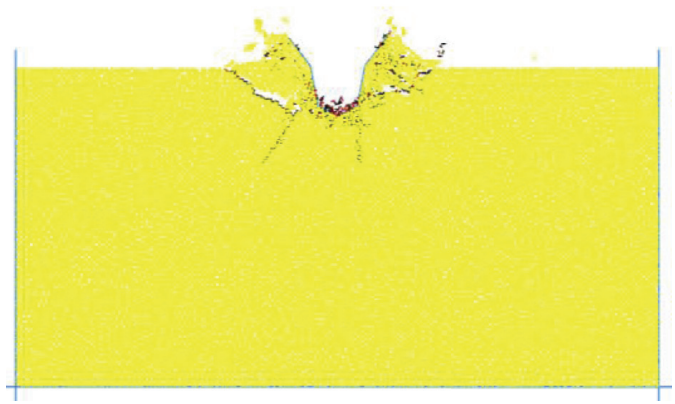

(b)

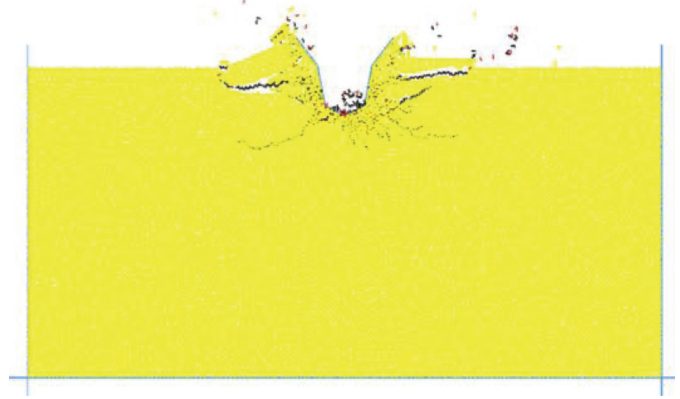

(d)

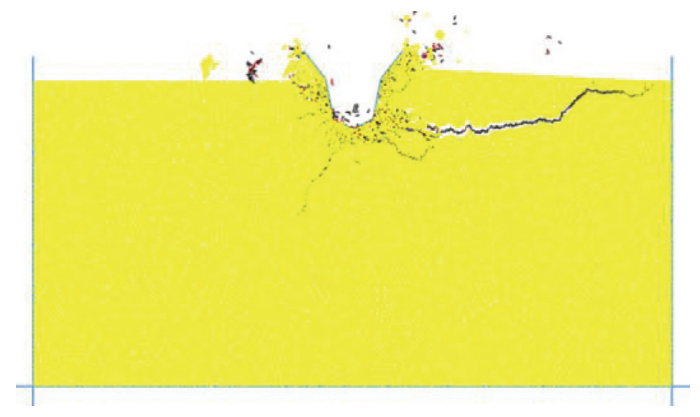

(e)

FiguRE 6: Failure characteristics of rock mass under different confining pressures: (a) $0.0 \mathrm{MPa}$, (b) $10.0 \mathrm{MPa}$, (c) $20.0 \mathrm{MPa}$, (d) $30.0 \mathrm{MPa}$, and (e) $40.0 \mathrm{MPa}$.

The number of microcracks under confining pressure is shown in Figure 7. The number of cracks under confining pressure is lower than that under no confining pressure. With the increase of confining pressure, the number of cracks gradually decreases. The vertical force of the disc cutter under confining pressure is shown in Figure 8. As the confining pressure increases, the disc cutter force gradually increases. This means that the confining pressure will limit the propagation of cracks. It is difficult to break the rock under confining pressure conditions than without confining pressure, and the degree of difficulty increases with the increase of confining pressure. The increase in confining pressure will inhibit the initiation of edge cracks and the propagation of the intermediate cracks in the crushing zone, and in the meanwhile, the depth of rock breaking will decrease, which is consistent with the conclusions obtained by Liu et al. [29] through theoretical derivation and laboratory experiments.

Synthesizing the rock-breaking modes of the disc cutter under different confining pressures, it can be obtained that the crack propagation has the following characteristics: (1) with the increase of the confining pressure, the depth of the crushing zone under the disc cutter becomes significantly smaller, that is, the increase in crustal stress will reduce the penetration depth of the disc cutter under the same disc cutter force; (2) the existence of confining pressure inhibits the longitudinal propagation of the central crack, which is beneficial to the propagation of transverse cracks; and (3) as the confining pressure increases, the depth and area of the crushing zone decrease, and the proportion of microcracks decreases.

4.2. Hob Spacing. Reasonable disc cutter spacing plays an important role in improving the rock-breaking ability of the disc cutter head and prolonging the service life of the disc cutter. In engineering, the disc cutter spacing of the cutter head is generally $60.0 \sim 120.0 \mathrm{~mm}$. In this section, the research method of dual disc cutters invading rock samples at the same time is used to analyze the influence of the distance 


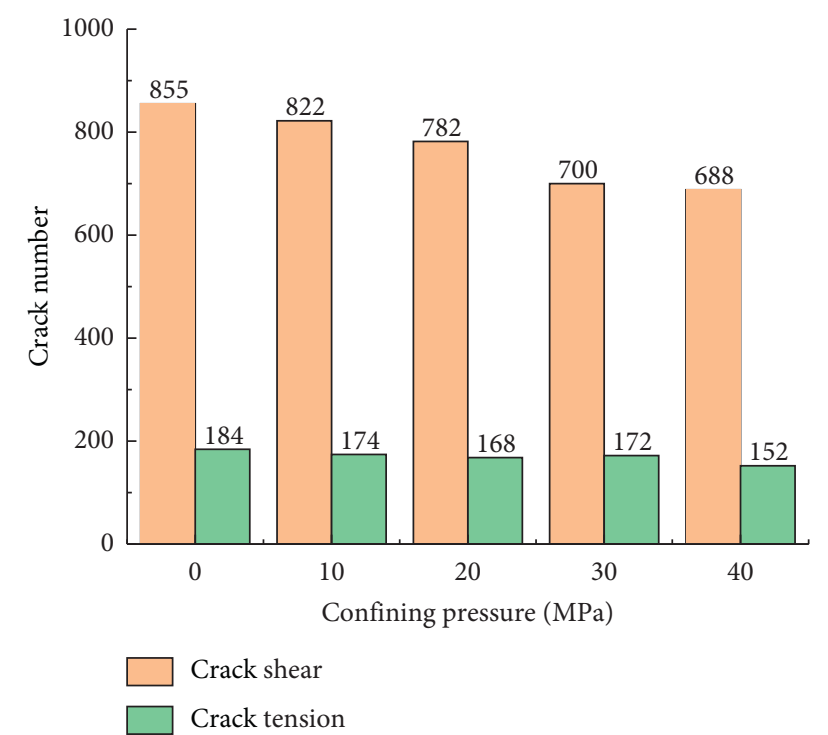

FIGURE 7: Statistics of the number of cracks under different disc cutter spacing.

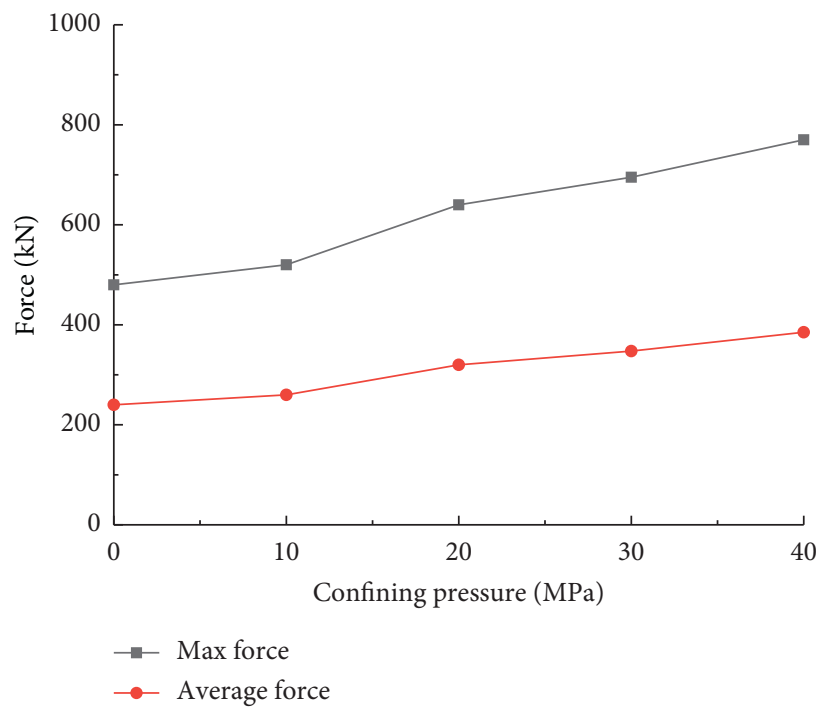

Figure 8: Vertical force of disc cutter under different confining pressures.

between the disc cutters on the rock-breaking process by means of numerical simulation.

When the distance between the disc cutters is small, the loaded energy causes the rock between the disc cutter edge to be broken, and the crack propagation mechanism is not fully utilized, resulting in low crushing efficiency (see Figure 9(a)). When the cutter spacing gradually increases but is less than $100.0 \mathrm{~mm}$, the damage and fracture of the rock mass between the hobs will cause the crack to penetrate at a certain depth and form flaky rock ballast (see Figure 9(c)). The size of the rock ballast increases with the increase of the disc cutter spacing. When the disc cutter spacing is $120.0 \mathrm{~mm}$, the damage caused by adjacent disc cutters did not cause the crack to penetrate, and the rock in the middle of the disc cutters forms an isolated rock ridge (see Figure 9(d)).
The number of cracks under different cutter spacing is shown in Figure 10. The number of cracks increases first and then decreases when the disc cutter spacing is from $60.0 \mathrm{~mm}$ to $120.0 \mathrm{~mm}$. The number of cracks is the largest when the spacing is $80.0 \mathrm{~mm}$. Therefore, if the disc cutter spacing is too large, the interaction between adjacent disc cutters cannot be fully utilized. In the process of cutting, there is an optimal disc cutter spacing, which makes the cutting specific energy consumption of the disc cutter lowest. When the disc cutters are arranged according to this optimal disc cutter spacing, taking the disc cutter spacing to an appropriate value will obtain higher cutting efficiency.

It can be seen from the figure that, within a certain range, the fragmentation of rock ballast increases with the increase of the disc cutter spacing. When the distance between the disc cutters is small, a large part of the rock between the two 


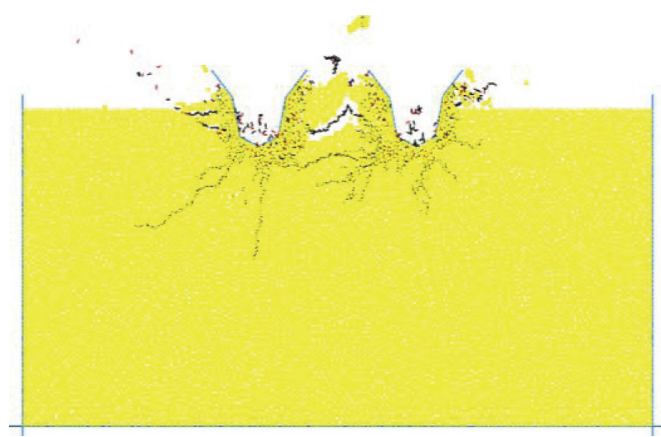

(a)

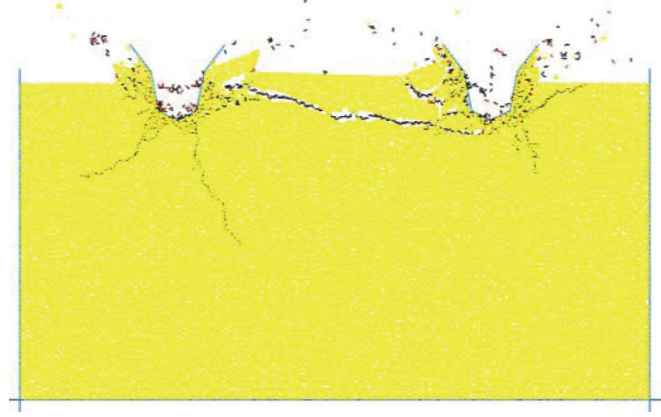

(c)

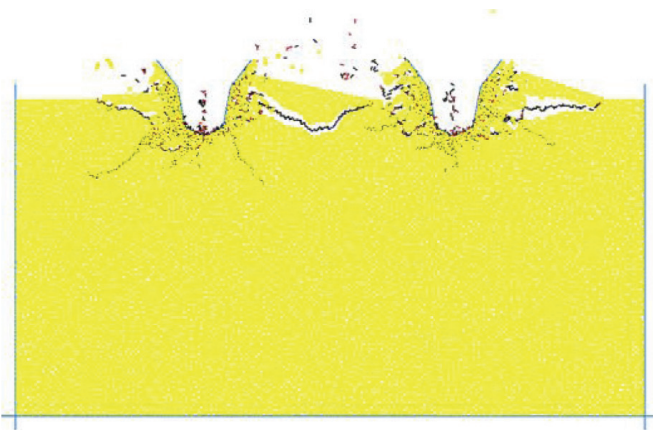

(b)

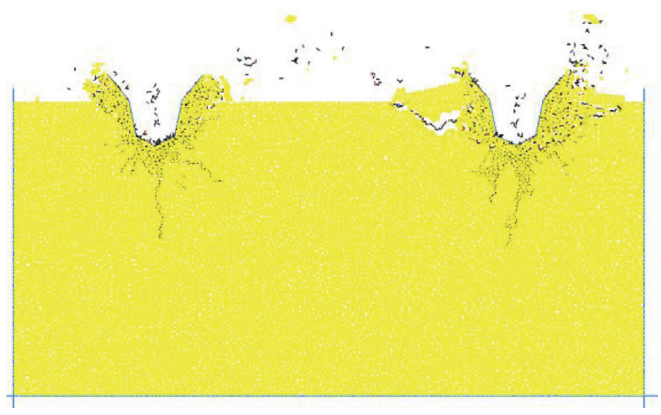

(d)

Figure 9: Crack propagation under different disc cutter spacing: (a) $60.0 \mathrm{~mm}$, (b) $80.0 \mathrm{~mm}$, (c) $100.0 \mathrm{~mm}$, and (d) $120.0 \mathrm{~mm}$.

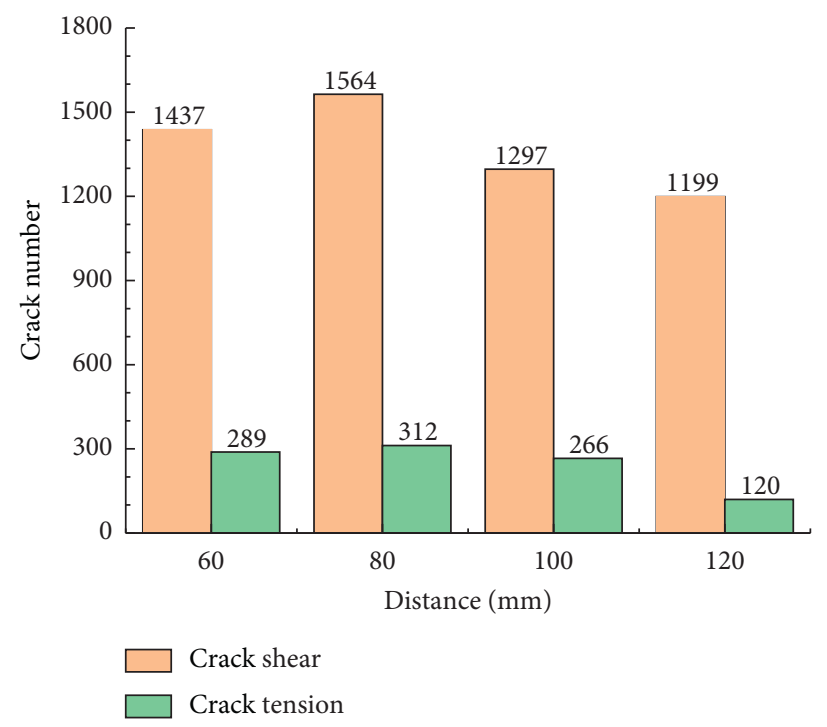

Figure 10: Statistics of the number of cracks under different disc cutter spacing.

disc cutters is still in the crushing zone, and the rockbreaking energy of the disc cutters fails to damage the deep rock, but to a large extent transforms into the crushing energy of the rock in the middle. When the disc cutter spacing is too large, the damage crack caused by a single disc cutter may be difficult to extend to $1 / 2$ of the disc cutter spacing, resulting in that although the rock in the middle of the disc cutter has the trend of forming massive rock ballast, some rocks are not broken and cannot be completely separated from the parent rock. Therefore, if the disc cutter spacing is too large, the interaction between adjacent disc cutters cannot be fully utilized. 


\section{Conclusions}

The following conclusions are drawn:

(1) Tensile and shear cracks appear simultaneously in the failure area under the edge of the disc cutter, with more shear cracks and fewer tensile cracks. The rock breaking by the disc cutter undergoes the transformation characteristics of compaction, shearing, and tension failure modes. The failure process of the rock mass is the joint action of tension and shear.

(2) In the initial stage of penetration, the vertical force of the disc cutter increases nearly linearly with the increase of penetration. When the penetration reaches $1.0 \mathrm{~mm}$, the vertical force drops abruptly, the disc cutter begins to unload, and the disc cutter has repeated loading-unloading alternate and rock breaking by leaping.

(3) After the penetration of the disc cutter reaches $9.0 \mathrm{~mm}$, penetration cracks begin to appear on the surface of the rock mass, the complete rock block is separated, and the falling rock block is formed.

(4) With the increase of confining pressure, the penetration is significantly reduced, mainly manifested as surface penetration cracks. The increase of confining pressure will inhibit the initiation of cracks at the edge of the crushing zone and the propagation of intermediate cracks, and in the meanwhile, the rockbreaking depth will be reduced.

(5) After the disc cutter spacing reaches $100.0 \mathrm{~mm}$, there are no penetration cracks between the two disc cutters, and the rock in the middle of the disc cutters forms an isolated rock ridge. If the disc cutter spacing is too large, the interaction between adjacent disc cutters cannot be fully utilized.

\section{Data Availability}

The data used to support the findings of this study are included within the article and can be available from the corresponding author upon request.

\section{Conflicts of Interest}

The authors declare that there are no conflicts of interest regarding the publication of this study.

\section{Acknowledgments}

This work was supported by Fundamental Research Funds for the Central Universities (Project no. FRF-TP-20-043A1), Open Research Fund Program of the State Key Laboratory of Hydroscience and Engineering (Project no. sklhse-2021-C04), and the Science and Technology Project of Huaneng Group Headquarters (Project no. HNKJ19-H15). The costs to publish in open access have been covered by the funding.

\section{References}

[1] S. F. Zhai, S. H. Cao, M. Gao, and Y. Feng, "The effects of confining stress on rock fragmentation by TBM disc cutters," Mathematical Problems in Engineering, vol. 2019, Article ID 5432470, 13 pages, 2019.

[2] G. Wang, T. Ren, and G. Zhu, "The influence of confining stresses on rock fragmentation, thrust force, and penetration energy in sandstone indentation tests using disc cutters," Advances in Civil Engineering, vol. 2021, Article ID 5541538, 13 pages, 2021.

[3] C. Cao and K. Zhang, "Systematic performance evaluation of shield TBM cutters for excavating multiple soft rock," Advances in Civil Engineering, vol. 2021, Article ID 4026283, 10 pages, 2021.

[4] L. Lin, Y. Xia, and D. Wu, "Multiobjective optimization design for structural parameters of TBM disc cutter rings based on FAHP and sampga," Advances in Civil Engineering, vol. 2019, Article ID 8438639, 13 pages, 2019.

[5] Q. Liu, Y. Pan, and P. Deng, "Mechanical and acoustic emission responses of rock fragmentation under disc cutter penetration," Advances in Civil Engineering, vol. 2021, Article ID 8829046, 17 pages, 2021.

[6] L. J. Yin, Q. M. Gong, H. S. Ma, J. Zhao, and X. B. Zhao, “Use of indentation tests to study the influence of confining stress on rock fragmentation by a TBM cutter," International Journal of Rock Mechanics and Mining Sciences, vol. 72, no. 2, pp. 261-276, 2014.

[7] J.-W. Cho, S. Jeon, H.-Y. Jeong, and S.-H. Chang, "Evaluation of cutting efficiency during TBM disc cutter excavation within a Korean granitic rock using linear-cutting-machine testing and photogrammetric measurement," Tunnelling and Underground Space Technology, vol. 35, no. 4, pp. 37-54, 2013.

[8] X. B. Zhao, X. H. Yao, Q. M. Gong, H. S. Ma, and X. Z. Li, "Comparison study on rock crack pattern under a single normal and inclined disc cutter by linear cutting experiments," Tunnelling and Underground Space Technology, vol. 50, pp. 479-489, 2015.

[9] J. Hassanpour, "Development of an empirical model to estimate disc cutter wear for sedimentary and low to medium grade metamorphic rocks," Tunnelling and Underground Space Technology, vol. 75, pp. 90-99, 2018.

[10] J.-H. Yang, X.-P. Zhang, P.-Q. Ji et al., "Analysis of disc cutter damage and consumption of tbm 1 section on water conveyance tunnel at lanzhou water source construction engineering," Tunnelling and Underground Space Technology, vol. 85, pp. 67-75, 2019.

[11] Z. Zhang, M. Aqeel, C. Li, and F. Sun, "Theoretical prediction of wear of disc cutters in tunnel boring machine and its application," Journal of Rock Mechanics and Geotechnical Engineering, vol. 11, no. 1, pp. 111-120, 2019.

[12] R. Gertsch, L. Gertsch, and J. Rostami, "Disc cutting tests in Colorado red granite: implications for TBM performance prediction," International Journal of Rock Mechanics and Mining Sciences, vol. 44, no. 2, pp. 238-246, 2007.

[13] L. Wang, Y. Kang, X. Zhao, and Q. Zhang, "Disc cutter wear prediction for a hard rock TBM cutterhead based on energy analysis," Tunnelling and Underground Space Technology, vol. 50, pp. 324-333, 2015.

[14] W. C. Maurer and J. S. Rinehart, "Impact crater formation in rock," Journal of Applied Physics, vol. 31, no. 7, pp. 1247-1252, 1960. 
[15] B. Chiaia, "Fracture mechanisms induced in a brittle material by a hard cutting indenter," International Journal of Solids and Structures, vol. 38, no. 44-45, pp. 7747-7768, 2001.

[16] Q. Geng, Z. Wei, and J. Ren, "New rock material definition strategy for FEM simulation of the rock cutting process by TBM disc cutters," Tunnelling and Underground Space Technology, vol. 65, pp. 179-186, 2017.

[17] J. Liu and J. Wang, "The effect of indentation sequence on rock breakages: a study based on laboratory and numerical tests," Comptes Rendus Mecanique, vol. 346, no. 1, pp. 26-38, 2018.

[18] Q.-M. Gong, J. Zhao, and Y.-Y. Jiao, "Numerical modeling of the effects of joint orientation on rock fragmentation by TBM cutters," Tunnelling and Underground Space Technology, vol. 20, no. 2, pp. 183-191, 2005.

[19] Q. M. Gong, Y. Y. Jiao, and J. Zhao, "Numerical modelling of the effects of joint spacing on rock fragmentation by TBM cutters," Tunnelling and Underground Space Technology, vol. 21, no. 1, pp. 46-55, 2006.

[20] P. A. Cundall and O. D. L. Strack, "A discrete numerical model for granular assemblies," Géotechnique, vol. 29, no. 1, pp. 47-65, 1979.

[21] M. J. Jiang, H.-S. Yu, and D. Harris, "A novel discrete model for granular material incorporating rolling resistance," Computers and Geotechnics, vol. 32, no. 5, pp. 340-357, 2005.

[22] M. Jiang, Z. Shen, and J. Wang, "A novel three-dimensional contact model for granulates incorporating rolling and twisting resistances," Computers and Geotechnics, vol. 65, pp. 147-163, 2015.

[23] M. J. Jiang, J. Liu, Z. F. Shen, and B. L. Xi, "Exploring the critical state properties and major principal stress rotation of sand in direct shear test using the distinct element method," Granular Matter, vol. 20, pp. 1-18, 2018.

[24] M. J. Jiang, Y. N. Liao, H. N. Wang, and Y. S, "Distinct element method analysis of jointed rock fragmentation induced by TBM cutting," Eur. J. Environ. Civ. En.vol. 22, no. suppl.1, pp. s79-s98, 2018.

[25] H. Huang, B. Lecampion, and E. Detournay, "Discrete element modeling of tool-rock interaction I: rock cutting," International Journal for Numerical and Analytical Methods in Geomechanics, vol. 37, no. 13, pp. 1913-1929, 2013.

[26] H. Huang and E. Detournay, "Discrete element modeling of tool-rock interaction II: rock indentation," International Journal for Numerical and Analytical Methods in Geomechanics, vol. 37, no. 13, pp. 1930-1947, 2013.

[27] E. Oñate and J. Rojek, "Combination of discrete element and finite element methods for dynamic analysis of geomechanics problems," Computer Methods in Applied Mechanics and Engineering, vol. 193, no. 27-29, pp. 3087-3128, 2004.

[28] S. Q. Kou, P.-A. Lindqvist, C. A. Tang, and X. H. Xu, "Numerical simulation of the cutting of inhomogeneous rocks," International Journal of Rock Mechanics and Mining Sciences, vol. 36, no. 5, pp. 711-717, 1999.

[29] H. Y. Liu, S. Q. Kou, P.-A. Lindqvist, and C. A. Tang, "Numerical simulation of the rock fragmentation process induced by indenters," International Journal of Rock Mechanics and Mining Sciences, vol. 39, no. 4, pp. 491-505, 2002.

[30] Q. M. Gong, J. Zhao, and A. M. Hefny, "Numerical simulation of rock fragmentation process induced by two TBM cutters and cutter spacing optimization," Tunnelling and Underground Space Technology, vol. 21, no. 3-4, pp. 263-270, 2006.

[31] X. X. Kong, Q. Liu, Y. F. Zhao, Y. Pan, and J. P. Liu, "Numerical simulation on the effect of joint orientation on rock fragmentation by TBM disc cutters," Journal of China Coal Society, vol. 40, pp. 1257-1262, 2015.

[32] T. Moon and J. Oh, "A study of optimal rock-cutting conditions for hard rock TBM Using the discrete element method," Rock Mechanics and Rock Engineering, vol. 45, pp. 837-849, 2012.

[33] S.-O. Choi and S.-J. Lee, "Three-dimensional numerical analysis of the rock-cutting behavior of a disc cutter using particle flow code," KSCE Journal of Civil Engineering, vol. 19, no. 4 , pp. 1129-1138, 2015.

[34] W. C. Maurer, "The state of rock mechanics knowledge in drilling," in Proceedings of the 8th Symposium on Rock Mechanics, pp. 355-395, University of Minesota, Minneapolis, MI, USA, September 1966.

[35] J. B. Cheatham and P. F. Gnirk, "The mechanics of rock failure associated with drilling at depth," in Proceedings of the 8th Symposium on Rock Mechanics, pp. 410-439, University of Minesota, Minneapolis, MI, USA, September 1966.

[36] P. F. Gnirk, "An experimental study of indexed single bittooth penetration into dry rock at confining pressures of 0 to 7500 psi," in Proceedings of the 1st Congress International Society on Rock Mechanics, pp. 121-129, International Society of Rock Mechanics, Lisbon, Portugal, September 1966.

[37] B. Lawn and R. Wilshaw, "Indentation fracture: principles and applications," Journal of Materials Science, vol. 10, no. 6, pp. 1049-1081, 1975.

[38] N. G. W. Cook, M. Hood, and F. Tsai, "Observations of crack growth in hard rock loaded by an indenter," International Journal of Rock Mechanics and Mining Sciences \& Geomechanics Abstracts, vol. 21, no. 2, pp. 97-107, 1984.

[39] M. Jiang, N. Zhang, L. Cui, and S. Jin, "A size-dependent bond failure criterion for cemented granules based on experimental studies," Computers and Geotechnics, vol. 69, pp. 182-198, 2015.

[40] J. H. Ren, Z. Y. Wei, and Q. Geng, "New rock material definition strategy for FEM simulation of the rock cutting process by TBM disc cutters," Tunnelling and Underground Space Technology, vol. 65, pp. 179-186, 2017.

[41] J.-W. Cho, S. Jeon, S.-H. Yu, and S.-H. Chang, "Optimum spacing of TBM disc cutters: a numerical simulation using the three-dimensional dynamic fracturing method," Tunnelling and Underground Space Technology, vol. 25, no. 3, pp. 230244, 2010.

[42] E. Oñate and J. Rojek, "Combination of discrete element and finite element methods for dynamic analysis of geomechanics problems," Computer Methods in Applied Mechanics and Engineering, vol. 193, pp. 3087-3128, 2004.

[43] C. Labra, J. Rojek, and E. Oñate, "Discrete/Finite element modelling of rock cutting with a tbm disc cutter," Rock Mechanics and Rock Engineering, vol. 50, no. 3, pp. 621-638, 2017.

[44] F. Wang, S. Liu, and K. Ji, "Numerical study on abrasive machining of rock using FDEM method," Simulation Modelling Practice and Theory, vol. 104, Article ID 102145, 2020.

[45] M. J. Jiang, W. Liu, B. L. Xi, and S. L. Jin, "Preliminary DEM analysis on micro-mechanical behavior of the composite cemented granules under complex stress conditions," in Proceedings of the 7th International Conference on Discrete Element Methods, vol. 188, pp. 525-534, Dalian, China, December 2016.

[46] M. J. Jiang, J. M. Konrad, and S. Leroueil, "An efficient technique for generating homogeneous specimens for DEM studies," Computers and Geotechnics, vol. 30, no. 7, pp. 579-597, 2003. 